\title{
A PRÁTICA INTERDISCIPLINAR NO AMBIENTE ESCOLAR
}

\section{THE INTERDISCIPLINARY PRACTICE AT SCHOLAR AMBIENCE}

\author{
Pamela Ullio $^{1}$, Rosana Ravaglia ${ }^{2}$ e Adilson Costa Filho ${ }^{1}$ \\ Mestrado em Ensino de Ciências da Saúde e do Meio Ambiente Centro Universitário de Volta Redonda \\ ${ }^{1}$ bethpam@superonda.com.br \\ ${ }^{2}$ rosana.ravaglia@foa.org.br \\ 3adilson.costa.filho@gmail.com.br
}

\section{Resumo}

Para resolver os problemas ambientais, são necessárias ações que estimulem a formação de um diálogo crítico entre a sociedade e o conhecimento científico. Apesar dos benefícios que estas práticas trazem, há o intenso predomínio de técnicas comportamentalistas. Diante dessa problemática, foi montado um projeto de Educação Ambiental envolvendo alunos de Ensino Médio de um colégio estabelecido na cidade de Resende-RJ, cujas atividades visaram a integração da saúde e do meio ambiente. Os participantes se sentiram agentes do aprendizado e chegaram a conclusão da necessidade da mobilização social e que temas como saúde e meio ambiente sejam abordados de forma integrada, para contribuir com a melhoria da qualidade de vida. A partir disso, pode-se concluir que mesmo com as dificuldades que se enfrenta para desenvolver práticas participativas, é necessário investir sobretudo no ambiente escolar onde a interação social se faz presente.

Palavras Chaves: Educação Ambiental; Educação em Saúde; Interdisciplinaridade

\begin{abstract}
To solve environmental problems is necessary actions that stimulate a critic dialogue between society and scientific knowledge. Despite of the benefits that these practices brings, are adopted behaviorists methods. Due to this trouble, was planed a project of environmental education with students of college class in a school in Resende-RJ, which activities aimed the integration among environmental and health. The participants felt actors from their learning and concluded the necessity of a society mobilization to contribute on the improvement of life's quality. Although the difficulties to develop interactive practice, is necessary to invest at scholar's environment.
\end{abstract}

Key words: Environmental Education, Health Education, Interdisciplinary

\subsection{Introdução}

A busca pela integração de pensamentos que objetivam o entendimento da realidade se faz presente na humanidade desde o início do pensamento filosófico. Ultimamente essa busca tem sido mais intensa devido a necessidade do entendimento dos fatores 
sociais visando a busca de soluções para os problemas ambientais que segundo Alves et al (2004), estão ligados a aspectos sociais, políticos econômicos e culturais. Para que isso aconteça, é necessário o uso de práticas que estimulam o diálogo transformador como a dialética que permite a construção do pensamento através de um consenso de ideias.

Ao promover o diálogo crítico, a dialética permite que seja colocada em prática o que Freire (2006), chama de princípio da práxis que é a associação da ação com a reflexão. A práxis leva o indivíduo a ter uma compreensão mais ampla da realidade, pois permite a formação do que Morin (2007) chama de pensamento complexo. Esse tipo de pensamento permite o questionamento da realidade através de uma interação entre várias disciplinas em torno de um tema chamado de interdisciplinaridade. Por isso que na opinião de Morin (2002), o ensino interdisciplinar é necessário para que se compreenda o todo, já que o conhecimento de uma disciplina complementa a outra.

A partir disso, o objetivo do trabalho, é analisar a importância da prática da interdisciplinaridade.

\subsection{A proposta interdisciplinar da Educação Ambiental e Educação em Saúde}

A necessidade de criar relações interdisciplinares para a conquista da melhoria da qualidade de vida, fez surgir práticas educacionais como a Educação Ambiental e a Educação em Saúde. Quando a interdisciplinaridade se faz presente, a Educação Ambiental e a Educação em Saúde tornam-se mais do que uma simples aquisição de conhecimento, mas a construção da cidadania.

A Educação Ambiental segundo Loureiro (2005), é um processo no qual são incorporados valores sócio-ambientais, ecológicos, éticos e emocionais ao processo educacional. Baseada na mobilização social preconizada Karl Marx, a Educação Ambiental pretende fazer essa mobilização através da formação da racionalidade ambiental que é um processo de produção teórica e de transformação social que tem por objetivo o desenvolvimento de práticas sociais que resultem em mudanças de hábito. A racionalidade ambiental é resultante de um saber ambiental que é o conjunto de saberes capazes de construir outros saberes que objetivam a elevação da qualidade de vida da população através da construção de uma nova organização social. (LEFF, 2006). 
Segundo Brasil (2002), Meyer et al (2006); Severo et al (2007), a Educação em Saúde é o nome dado ao conjunto de práticas educacionais que possibilita além da qualificação dos profissionais, o desenvolvimento da qualidade de vida que é definida por Forattini (2004), como os fatores sociais e ambientais que interferem nas necessidades biológicas e psíquicas.

A prática da Educação em Saúde como ferramenta na conquista da qualidade de vida tem como base a definição de saúde pela Constituição da Organização Mundial de Saúde que diz que saúde é um estado de bem-estar bio-psiquicosocial. Para que a Educação em Saúde cumpra com o seu objetivo, surge a promoção da saúde que é um processo de capacitação comunitária que utiliza uma combinação de componentes ambientais e educacionais aliados a participação popular. Dessa forma, o indivíduo é capaz de tomar decisões conscientes e contribuir com a qualidade de vida. Além disso, a doença que antes era tratada como um mal individual, passa a ser tratada como um fenômeno social que estimula a busca da origem da doença e também a conquista de outros valores como paz, educação, alimentação saudável, renda suficiente, ecossistema saudável, justiça social e equidade. (SÍCOLI \& NACIMENTO, 2003; OLIVEIRA, 2005)

\subsection{A realidade da Educação Ambiental e da Educação em Saúde no Brasil}

Apesar da transformação que a Educação Ambiental e Educação em saúde proporcionam a partir da proposta interdisciplinar, são adotados nestas áreas práticas comportamentalistas.

Loureiro (2005); Guimarães (2004), comentam que instrumentos legais como os Parâmetros Curriculares Nacionais e a Lei Federal que define a Política Nacional de Educação Ambiental (Lei 9795/1999), asseguram a prática da Educação Ambiental no ambiente escolar, mas o que se encontra são práticas descontextualizadas, voltada para a memorização e para a adoção de comportamentos que visam a preservação da natureza.

Loureiro (2006), diz que essa disparidade ocorre entre os aspectos legais e a realidade é em virtude da forma em que a lei que define a Política Nacional de Educação Ambiental foi formulada, porque durante sua formulação não houve a participação dos educadores ambientais e as bases legais que sustentam o documento 
estão fora das condições sociais, acadêmicas e políticas. Em conseqüência desse fato, encontra-se uma lei que ao mesmo tempo une o ambiente à cultura, impõe um comportamento naturalista, reduzindo a possibilidade de politizar as questões expostas pela Educação Ambiental

A prática comportamentalista na Educação em Saúde é encontrada na prevenção de doenças por meio da adoção de hábitos saudáveis que são passados através de informações fornecidos por profissionais da saúde. Esta prática além de culpar o indivíduo por não adquirir hábitos prescritos pela medicina, pune-o pela manifestação da doença.

Morin (2007) compara o hábito de introduzir conteúdos a uma seção de hipnose onde a pessoa recebe novos hábitos que ainda não foram despertados. O exemplo que ele dá é a de um fumante que não pediu para parar de fumar, de repente se vê com informações de que deveria parar de fumar e num passe de mágica todos aqueles anos que fumou deveriam desaparecer na troca de não ter câncer de pulmão.

Segundo Gazzinelli et al (2005), a prática comportamentalista da Educação Ambiental e da Educação em Saúde é herança do método cartesiano que domina as práticas educativas atuais. Dessa forma é possível dividir tanto a Educação Ambiental como a Educação em Saúde em duas correntes distintas: Uma comportamentalista a qual prevalece a transmissão de informações prontas e uma crítica em que a conscientização ocorre através de uma interação dialógica.

A prática comportamentalista é questionada por vários estudiosos até mesmo pela Organização Mundial da Saúde (OMS), por constatar que grande parte da população não muda de hábitos quando está em contato com o método. Para Jacobi (2003); Chassot (2006); Leff (2001), a corrente que é capaz de auxiliar na transformação social é a crítica por que ao estimular a participação, o indivíduo é estimulado a criar novas atitudes, se sentindo responsável pelos atos, sem a necessidade de impor normas e aplicar meios punitivos que insinuam a culpa, formando cidadãos.

\subsection{A integração entre educação Ambiental e Educação em Saúde}

Há uma tentativa também de estabelecer uma relação interdisciplinar entre saúde e meio ambiente a fim de compreender melhor a relação homem, saúde e meio ambiente. De acordo com Junior et al (2005), a OMS apóia essa integração através da Carta de Ottawa, documento resultante da I Conferência Internacional sobre políticas de 
saúde realizada em 21 de novembro de 1986 no Canadá.

Apesar de todo o esforço que tem-se feito, ainda persiste o enfoque medicamentoso da saúde, e ecológico do meio ambiente, principalmente no meio acadêmico. Forattini (2004), relata que a união da saúde com o meio ambiente, está sendo utilizada para integrar a medicina preventiva e a epidemiologia para entender melhor a gênese da doença a nível populacional, mas não há . Freitas (2003); Leff (2006), dizem que a dificuldade de unir o meio ambiente ao contexto social é devido à falta de abertura que ocorre nas ciências sociais em razão de sua trajetória especialmente na sociologia.

Leff (2006), diz que para a integração entre saúde e meio ambiente só terão efeito transformador, quando houver a incorporação das ciências sócias. A inserção do contexto social no conhecimento científico é importante porque estimula a relação dialógica entre o entendimento científico e o entendimento popular através das discussões que são traçadas.

\subsection{Metodologia}

A partir da constatação da necessidade da aplicação de práticas interdisciplinares no ambiente escolar, foi realizado um projeto de Educação Ambiental que envolveu alunos do Ensino Médio do Colégio Estadual Doutor João Maia situado na cidade de Resende-RJ em encontros semanais de 100 minutos. Utilizando as instalações da escola, os alunos selecionados de acordo com a disponibilidade e o consentimento dos pais, participaram de atividades como dinâmicas, vivências, visitas que pudessem ao estabelecer uma relação entre saúde e meio ambiente criar discussões em cima da problemática da água.

A pesquisa realizada é do tipo qualitativa, já que envolveu a observação do comportamento dos participantes durante o projeto. (MENEZES \& SILVA, 2001).

\subsection{Discussão}

As atividades desenvolvidas pelo projeto propiciaram que os participantes tivessem um pensamento questionador e crítico sobre o tema proposto. O entusiasmo que desenvolveram, estimularam a ter um olhar mais atento sobre a problemática da 
água, levando-os a pesquisar mais sobre o tema e elaborar produtos que pudessem estabelecer um diálogo entre eles e a comunidade como um panfleto, uma peça de teatro e um jogo. Essa preocupação dos alunos, condiz ao que Guimarães (2004), comenta que a comunidade deve estar envolvida no processo educacional de forma a possibilitar a modificação da realidade local.

De acordo com os alunos, o projeto o fez sentir agentes do aprendizado e o que facilitou nesse processo foi quando entenderam a importância de integrar saúde e meio ambiente, pois viram que os problemas relativos a essas áreas estão relacionadas e interferem na qualidade de vida da população. A princípio tiveram dificuldade de fazer essa relação, já que eles não conheciam da existência dessa relação. O que facilitou o entendimento foi um passeio de barco realizado na parte onde o rio Paraíba do Sul banha o centro urbano de Resende-RJ.

Durante o trajeto estabelecido, os alunos fizeram uma relação dos impactos ambientais que viram e logo após foram convidados a dividir os impactos que estavam ligados a saúde e ao meio ambiente. Quando se abriu para discussões, os alunos perceberam que os impactos ligados ao meio ambiente e a saúde relacionavam-se entre si não havendo possibilidade de separação. Um exemplo mencionado foram as casas construídas na beira do rio. A princípio é um problema ambiental que provoca o assoreamento do rio pelo desmatamento da margem e o desequilíbrio do ecossistema, pela falta da mata ciciar, prejudicando a cadeia alimentar. Por outro lado, essas moradias prejudicam a saúde da população que as habitam por que os levam a ter uma preocupação com a elevação da água do rio em épocas chuvosas e com o desabamento da construção pela fragilidade do terreno desmatado, além da possibilidade de patologias que poderá ter se entrar em contanto com a água suja que, já que não há tratamento de esgoto. Além disso, o esgoto também é um problema ambiental porque contribui para a diminuição da quantidade de oxigênio da água e aqueles que estiverem próximos ao rio, não vão se sentir bem por causa do mau-cheiro que a matéria orgânica em decomposição exala.

Assim, eles concluíram que além de não ser possível separar os problemas relacionados a saúde e ao meio ambiente, para modificar o cenário que se encontra no rio, é necessário uma mobilização da população e que os problemas levantados fossem abordados como comprometedores da qualidade de vida. 


\subsection{Conclusão}

Apesar de existirem dificuldades que impeçam o desenvolvimento de práticas participativas, elas devem ser incentivadas, pois é a partir da formação de um ambiente favorável ao diálogo crítico, que o indivíduo é capaz de ter uma escolha livre e consciente.

Por ser um espaço de interação social, a escola é um local propício para a dialética. Para isso, as atividades pedagógicas devem estar voltadas para desenvolver competências que estimulem esta prática.

A interdisciplinaridade é uma prática transformadora, pois diversas áreas se reúnem em torno de um tema e se interage numa relação dialógica, mas para que contribua com a transformação social, é necessário que haja a participação social a fim de estimular a prática da práxis que é a reflexão teórica aliada à prática.

O projeto desenvolvido mostrou que a possibilidade de inserir a saúde e o meio ambiente na Educação Ambiental garante a sua prática crítica através da sua prática interdisciplinar e a incorporação da relação social na saúde. Dessa forma, o homem se sente parte integrante do meio ambiente, ao ter uma visão ampla da realidade e capaz de lutar por uma melhor qualidade de vida.

\section{Referências bibliográficas}

BRASIL. Ministério da Saúde. A promoção da saúde no contexto escolar [online]. Revista de Saúde Pública, n.4, v.36, p.533-5, 2002.

ALVES, R. F. et al, Interdisciplinaridade; um conceito em construção. Episteme, Porto Alegre, n. 19, p. 139-148, jul./dez. 2004.

CHASSOT, A. Alfabetização Científica. 4ed: Injuí: Ijuí, 2006.

FORATTINI, O. P. Ecologia, epidemiologia e sociedade. 2ed. Artes Médicas: São Paulo, 2004.

FREIRE, P., Pedagogia do Oprimido. 44ed. Paz e Terra: São Paulo, 2006.

FREITAS, C. M., Problemas ambientais, saúde coletiva e ciências sociais. Ciência \& 
Saúde Coletiva, v.8, n.1, p. 137-150, 2003.

GAZZINELLI, M. F. et al, Educação em saúde: conhecimentos, representações sociais e experiências da doença Caderno de Saúde Pública, Rio de Janeiro, 21(1):200-206, jan-fev, 2005

GUIMARÃES, M. Formação de educadores ambientais Papirus: 2004 São Paulo.

JACOBI, P. Educação Ambiental, Cidadania e sustentabilidade Cadernos de Pesquisa, São Paulo, n. 118, p.189-205 março, 2003.

JUNIOR, H. S. A.; BROCHIER M. A., Representação social da educação ambiental e da educação em saúde em universitários. Psicologia Reflexiva Crítica, Porto Alegre, v. 17 , n. 1,2004

LEFF, E., Saber Ambiental. Vozes: Petrópolis, 2001.

LEFF, E., Racionalidade Ambiental e a reapropriação social da natureza. Record: Rio de janeiro, 2006.

LOUREIRO, C.F.B. Trajetória e fundamentos da Educação Ambiental. Cortez: São Paulo, 2004.

LOUREIRO, C.F.B., Complexidade e Dialética: contribuições à Práxis Política e emancipatória em educação Ambiental Educ. Soc., Campinas, v. 26, n. 93, p. 1473 1494, Set./Dez. 2005.

LOUREIRO, C.F.B. Pensamento complexo, dialética e Educação Ambiental. Cortez: São Paulo, 2006.

MENEZES, E. M. e SILVA, E. L. Metodologia da pesquisa e elaboração de dissertação. 3ed.

http://projetos.inf.ufsc.br/arquivos/Metodologia\%20da\%20Pesquisa\%203a\%20edicao.p df , acessado no dia 26/05/2009.

MEYER, D. E. E., et al. "Você aprende. A gente ensina?" Interrogando relações entre educação e saúde desde a perspectiva da vulnerabilidade Caderno de Saúde Pública, Rio de Janeiro, n 22, v.6 p.1335-1342, jun, 2006.

MORIN, E. et al, Diálogo sobre o conhecimento. São Paulo: Cortez, 2004.

MORIN, E., Introdução ao pensamento complexo. 3ed. Porto Alegre: Sulina, 2007.

OLIVEIRA, D. L. A. 'nova' saúde pública e a promoção da saúde via educação: entre a tradição e a inovação. Revista Latino Americano Enfermagem, São Paulo, v.13, n. 3, p. 423-31, maio- junho, 2005

SEVERO, et al, 2007 Articulação nacional de movimentos e práticas de educação popular e saúde no estado de Santa Catarina: Fortaleza e fragilidades. Contexto Revista Eletrônica do Mestrado Profissional em Ensino de Ciências da Saúde e do Ambiente 
Enfermidade, Florianópolis, v. 16, n. 2, p. 239-245, Abr-Jun, 2007

SÍCOLI, J. \& NASCIMENTO, P.R., Promoção de saúde: concepções, princípios e Operacionalização. Interface - Comunicação, Botucatu, v.7, n.12, p.91-112, 2003. 